The International Journal Of Engineering And Science (IJES)

|| Volume || 6 || Issue || 3 || Pages || PP 106-115|| 2017 ||

ISSN (e): $2319-1813 \operatorname{ISSN}$ (p): $2319-1805$

\title{
Experimental Determination of Fracture Energy by RILEM Method
}

\author{
Naik Partha Uday \\ Department of Civil Engineering, MGM College of Engineering, Kamothe.
}

\begin{abstract}
-
This paper deals with investigation of fracture energy $\left(G_{F}\right)$ of concrete. The study involves experimental determination of fracture energy $\left(G_{F}\right)$ by testing three point bend concrete beams of same size but varying notch to depth ratios. RILEM fracture energy $\left(G_{F}\right)$ and Stress Intensity factor values is determined.
\end{abstract}

Keywords: Concrete, Fracture mechanics, RILEM fracture energy, fracture toughness, , three point bending, stress intensity factor.

Date of Submission: 14 March 2017

$\longrightarrow$ Date of Accepted: 25 March 2017

\section{INTRODUCTION}

Concrete, due to its excellent shielding capability, fire rating, long service life under normal and accidental conditions and ease in construction with relatively lower cost, is used extensively in building most of the civil engineering structures. In-spite of such salient features, the concrete structures generally consist of numerous micro-cracks that might result in fracture of the concrete structures under service loads, accidental load and/or exposure to regular environmental conditions. Thus a micro-crack in concrete may become a potential source of crack propagation leading to a probable catastrophic failure. In order to prevent such accidents, it is necessary to predict the failure mechanisms of structures, so that the safety of concrete structures throughout the service life can be assured. The failure mechanism can be studied by quantifying the energy consumed in crack propagation and formation of new crack surfaces. In a concrete structure, the crack growth requires a certain amount of energy that can only be studied through an energy based propagation criterion, which provides a fundamental basis for understanding the phenomenon of concrete fracture mechanism. ${ }^{[10]}$

Concrete despite predominantly elastic material response, exhibits a stable non-linear fracture response in tension loading, when tested under displacement control. The reason for the non-linearity is the development of a fracture process zone (FPZ) ahead of the crack tip. In a quasi brittle material like concrete the energy dissipated for the formation of FPZ ahead of the crack tip, is termed as fracture energy. The concrete fracture energy characterizing the failure process is still under extensive research. The size-independent fracture energy is the most useful parameter in the analysis of cracked concrete structure. The present study investigates an easy and robust technique for the determination of the size independent fracture energy of concrete.

Following are the main objective of the present study:

1. To study Fracture mechanics, concrete behaviour, failure mechanism and load bearing capacity of concrete structures.

2. To study concrete as a quasi-brittle material through load displacement curve.

3. To study crack propagation of pre-notched beams.

4. To calculate Fracture Energy and study variation of same with respect to varying notch to depth ratio.

Fracture mechanics is in developing stage thus there are many things to research. In this present study, Fracture Energy which is one of the important parameter will be calculated using work energy method. The method used is the best technique and approved by RILEM, thus the name RILEM method.

The present work is restricted considering the experimental testing to be done. Study involves experimental testing of pre-notched beams under three point bending. Beams of same size but with varying notch to depth ratio are used. Mathematical modelling of present work is out of scope.

\section{LITERATURE SURVEY}

There are many research carried on Fracture Mechanics now-a-days. Some of the papers which I found important for my research are reviewed and discussed here. In first paper by S.Y. Alam, A. Loukili, F. Grondin, E. Rozière, June 2015, "Use of the digital image correlation and acoustic emission technique to study the effect of structural size on cracking of reinforced concrete ${ }^{\text {[12] }}$ an experimental investigation is performed by employing two experimental techniques simultaneously i.e. digital image correlation and acoustic 
emission to study the degradation of reinforced concrete beams. The first method gives precise measurement of surface displacements, thus crack openings and crack spacing are determined. In order to complement this method and to investigate damage mechanisms, acoustic emissions resulting from internal damage are also analysed. To study the effect of structural size Beams of three different sizes but proportionally similar, were tested. Experimental measurements were compared with Euro-code expressions.

Based on results, following things were concluded. Bending tests were performed on reinforced concrete beams. In the first part of the study, under service loading, comparison of Euro-code expressions for crack openings and cracks spacing and experimental measurements were done. At low strains and for the smallest beam size the results show that the measured values more or less agree with the calculated values. However, as the strain increases, the Euro-code expressions underestimate the crack openings and spacing. As the size of the beam increases the discrepancy between Euro-code estimation and experimental measurements of crack openings and crack spacing increases. It seems that difference in expressions is due to the shift in failure modes observed when the size of the specimen increases, which is not taken in account in expressions.

Micro-cracking is studied through AE parametric analysis in the second part of the study,. AE hits and AE energy are analysed in the top and bottom sensors. Larger the beam size, the number of hits and AE energy released are low during the initial loading stages. The AE energy release is more abrupt in larger beam (D3) at peak load, while in the smaller beams it is quasi-continuous. A grouping method (similar to K-means method) is used to identify different classes of AE energy released. For these classes, when the size increases from small to large beams, AE parameters are analysed to identify micro-cracking and macro-cracking phases. The conclusions are based on the results obtained on 1:3 scale. As the fracture process is more complex in reinforced concrete as compared to plain concrete, more conclusive results may be obtained on a wider scale.

In next paper by, A. Nazari, J.G. Sanjayan, June 2015, "Stress intensity factor against fracture toughness in functionally graded geo-polymers" ${ }^{[13]}$ the benefits of producing functionally graded geo-polymer in terms of their modified stress intensity factor and fracture toughness are discussed. Pre-notched functionally graded geo-polymer beams were fabricated by two different fly ash-based geo-polymer mixtures. The load was applied parallel to the functionally graded region; two different structures were evaluated by changing the position of the notch. The obtained results indicated that the crack nucleation and growth depend on the interaction between stress intensity factor and fracture toughness. A crack facing an upward fracture toughness region is arrested, when the applied stress is equal to the weakest strength of the constituent materials. On the other hand, the fracture toughness of a crack facing a downward fracture toughness gradient is more than that facing an upward one, without any subsequent arresting. It was shown that the position of the notch, and experiencing of downward or upward gradient in mechanical properties mainly determine the final flexural strength of the specimens.

Following conclusions were made in this paper. A modification method was proposed to the variations of stress intensity factor, $\mathrm{K}$, in FGG specimen. At first, fracture toughness, $\mathrm{K}_{\mathrm{c}}$, of functionally graded region was suggested to change exponentially. By intersecting the curves of $K_{\text {and }} \mathrm{K}_{\mathrm{c}}$, fracture toughness of functionally graded specimens was determined. However, to deliver a comprehensive formulation of $\mathrm{K}$, a modification procedure was carried on. In addition to the variations of $\mathrm{K}$ in functionally graded region, the post monolithic region in FGG is affected by the variation of $\mathrm{K}$ in functionally graded region. A modification factor of elastic modulus ratio was proposed to determine the effect of notch position on fracture toughness of specimens. While both specimens consist of G1 and G2 monolithic specimens, the fracture energy strongly depends on the notch tip position. Regardless of the content of constituent materials, upward and downward changes of mechanical properties determine the crack initiating and propagating across the FGG specimens. This modification factor is not observed in most theoretical models and only variation of properties in graded region is considered. However, experimental observations in this paper show this important difference feature.

Paper by Xiufang Zhang, Shilang Xu, March 2011, "A comparative study on five approaches to evaluate double-K fracture toughness parameters of concrete and size effect analysis" ${ }^{111]}$ discussed here. Using experimental method and four existing analytical methods, the current paper presents a comprehensive comparison of double-K fracture toughness parameters of concrete evaluated. Fracture tests were carried out on compact tension wedge splitting specimens with various depths varying from $200 \mathrm{~mm}$ up to $1000 \mathrm{~mm}$. In the analytical calculation, depending on the relationship between critical crack tip opening displacement and the abscissa value of turning point on bilinear softening curve, two different distributions of cohesive stress are considered along crack extension. Four available analytical calculations yield almost the same values of double$\mathrm{K}$ fracture toughness parameters and agree well with those obtained from the experiment, which confirms the consistency of five approaches.

He concluded that, crack development process from initial cracking to stable propagation to unstable propagation in concrete may be well described through double-K fracture model in which two fracture control parameters, called double-K fracture toughness, i.e., initiation fracture toughness and unstable fracture toughness are introduced. In this study, a comparison of double-K fracture toughness parameters determined 
from the experimental measurements and four existing analytical solutions, i.e., Gauss-Chebyshev integral method, simplified equivalent cohesive force method, simplified Green's function method and four terms weight function method, was done on the compact tension wedge splitting specimens with various depths. It must be stressed in the calculation of cohesive fracture toughness that when large specimens are considered, the value of the critical crack tip opening displacement $\mathrm{CTOD}_{\mathrm{c}}$ is usually higher than that of $\mathrm{w}_{\mathrm{s}}$ on the bilinear softening curve. The assumption of the linear cohesive stress distribution along crack extension is inapplicable for large specimens especially ones with depth of more than $600 \mathrm{~mm}$, which was adopted in the previous studies for smaller specimens. From size effect analysis, the following main conclusions can be made:

a) unstable fracture toughness and initiation fracture toughness are not much affected by the specimens depth, with the average value of about $1.656 \mathrm{MPa}-\mathrm{m}^{1 / 2}$ and $0.806 \mathrm{MPa}-\mathrm{m}^{1 / 2}$, respectively;

b) as the depth of specimen increases up to about $600-800 \mathrm{~mm}$ depth range, both the extending critical fracture process zone $\left(\mathrm{a}_{\mathrm{c}}-\mathrm{a}_{\mathrm{o}}\right)$ and critical crack tip opening displacement CTODc are shown to increase. Beyond this range, they appear to alter little and may be considered as material properties.

Lastly, paper by N. Trivedi, R.K. Singh, J. Chattopadhyay, March 2015," A comparative study on three approaches to investigate the size independent fracture energy of concrete" ${ }^{\prime[10]}$ discussed here deals with investigation of size-independent fracture energy $\left(\mathrm{G}_{\mathrm{f}}\right)$ of concrete. The study involves numerical modelling of three point bend concrete beams that are geometrically similar having constant length to depth ratio with varying notch to depth ratios. Values evaluated numerically and experimentally for RILEM fracture energy $\left(\mathrm{G}_{\mathrm{f}}\right)$ are found to be in reasonable agreement. $G_{f}$ is estimated from developed relationship of fracture energy release rate and through bilinear model by $\mathrm{G}_{\mathrm{f}}$ values. $\mathrm{G}_{\mathrm{f}}$ values have been utilized t odevelop a simple methodology for estimation of $\mathrm{G}_{\mathrm{f}}$. Comparative analysis

has been carried out for $\mathrm{G}_{\mathrm{f}}$ from three different methodologies.

Based on results he concluded, the size-independent fracture energy of concrete is the most useful parameter in the analysis of cracked concrete structure which is investigated in the present work. The finite element simulations of the TPB specimens of different sizes with $\mathrm{a} / \mathrm{W}=0.05,0.25$ and 0.33 are performed by incorporating the concrete properties based on fracture energy strain softening model. Following conclusions are drawn from the above study:

- The estimated RILEM fracture energy $\left(\mathrm{G}_{\mathrm{f}}\right)$ values of concrete from the numerically predicted and experimentally observed load-load line displacement curves are found to be in reasonably good agreement.

- The present work develops an easy and robust technique for the determination of the size independent fracture energy of concrete. The study also invokes a primary approach based on concrete fracture mechanics that describes the nonlinear aspects of concrete behaviour through load-load line responses for a range of a/W ratios and help to understand the failure mechanisms and load bearing capacity of concrete structures.

- A comparative analysis of 3 methods used to measure the size-independent fracture energy of concrete has been carried out. The observed values of $\mathrm{G}_{\mathrm{F}}$ from the three methodologies are found to be in reasonable agreement. It is, therefore, concluded that either method can be used to obtain a unique value of the sizeindependent fracture energy of concrete due to consistent trend of fracture energy values evaluated by all methods.

Literature presented above shows many research are going on the Fracture parameters like Fracture Energy " $\mathrm{G}_{\mathrm{f}}$ " and Stress Intensity Factor " $\mathrm{K}_{\mathrm{IC}}$ " due to their importance in Fracture Mechanics. Various methods are used to determine this parameters, but most simple and best technique approved by RILEM is Work of Fracture Method which is also known as RILEM method.

The fracture parameters " $\mathrm{G}_{\mathrm{f}}$ " \& " $\mathrm{K}_{\mathrm{IC}}$ " are size independent thus it does not vary with size of structure if they are geometrically similar.

\section{THEORITICAL BACKGROUND}

The material fracture properties are characterised by only three parameters - Fracture Energy, Uni-axial Strength Limit and Width of the Crack Band ( Fracture Process Zone), while strain softening modulus is a function of theses parameters. The fracture energy of concrete is the most important parameter in the fracture behaviour of concrete that describes the mechanism of cracking. The commonly used method for measuring the fracture energy is the work-of-fracture method recommended by RILEM.

The total energy of fracture includes all the energy dissipated per unit propagation distance of the fracture process zone as a whole. This is called the Fracture Energy " $G_{\mathrm{f}}$ ". The fracture toughness " $\mathrm{G}_{\mathrm{c}}$ " defined by LEFM is equal to Fracture Energy " $\mathrm{G}_{\mathrm{f}}$ ". 
Work of Fracture Method: ( RILEM )

This method, which was originally developed for ceramics is the first method of testing for fracture properties of concrete to be proposed as a standard (RILEM, 1985). The basis for applying this method to concrete was developed by Hillerborg and his co-workers. Their method uses the "fictitious crack" concept.

The method can be applied to a variety of test specimen geometries but the proposed standard uses a beam specimen loaded in three point bending with a central edge notch. RILEM technical committee recommended the guidelines for determination of fracture energy of cementitious materials by conducting TPB test on notched beam as shown in fig. 1. In order to obtain a complete load and load point displacement curve, a closed loop servo hydraulic testing machine is recommended.

The fracture behaviour of concrete characterized by the RILEM measures the averaged fracture energy over the entire projected ligament area.

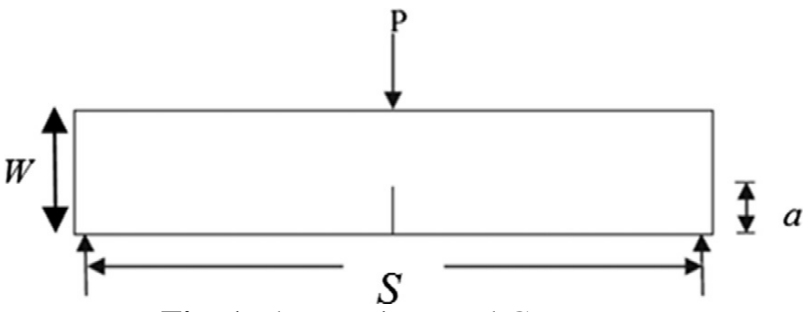

Fig. 1 Three Point Bend Geometry

According to RILEM recommendation, the fracture energy is evaluated by dividing the total applied energy with the projected ligament area. Briefly, the test procedure consists of the following steps :

1. The beam proportions are selected in relation, to maximum aggregate size. The minimum depth $d$ is approximately six times the size of the aggregate.

2. The vertical load-point deflection of the beam is to be measured and plotted continuously along with the applied load $\mathrm{P}$.

3. The test is to be conducted in a manner to produce stable crack growth. If closed-loop testing is used then strain control should be selected. If a closed-loop system is not available, then a stiff testing machine is required.

Therefore, for a specimen with a depth "W" and an initial crack length "a" as shown in fig. 1, the "G $\mathrm{G}_{\mathrm{f}}$ is given as:

$$
\mathrm{G}_{\mathrm{f}}(\alpha, \mathrm{W})=\frac{1}{(W-\sigma) B} \int \mathrm{P} \mathrm{d} \partial
$$

where, $\alpha=\mathrm{a} / \mathrm{W}$ i.e notch to depth ratio.

Materials used:

\section{EXPERIMENTAL WORK}

Cement: Ordinary Portland cement 43 grade conforming to Indian standard specification (IS:269-1976) was used.

Aggregate: Sand obtained from local river beds was used as fine aggregate. Aggregate of maximum size $20 \mathrm{~mm}$ was used as coarse aggregate.

Water: Ordinary potable water was used.

Mix Adopted:

A concrete mix of 1:1:2 by weight with a water cement ratio of 0.45 was used. Generally this proportion of mix gives M25 grade concrete.

Casting and curing of specimens:

The notch is made by using a Plywood of $2-3 \mathrm{~mm}$ thickness of required size. Concrete was poured in three layers and vibrated. Plywood was removed after 3-4hrs when initial setting of concrete is passed. After 24 hours of the casting of the beam the mould was removed. Specimens were cured in a curing tank for 28 days.

\section{Test Specimens:}

A total of 18 beams were cast for testing. All 18 beams were of same size having different notch to depth ratio. In each beam notch was at the centre.

Beams are divided into 3 types P1, P2 \& P3 depending on notch to depth ratio. Six number of beams are cast for each type of beam. Following are the details: 
Table 1. Beam Specification

\begin{tabular}{|l|l|l|}
\hline Beam Type & Beam Size & Notch to depth ratio \\
\hline P1 & $700 * 150 * 150$ & 0.15 \\
\hline P2 & $700 * 150 * 150$ & 0.35 \\
\hline P3 & $700 * 150 * 150$ & 0.50 \\
\hline
\end{tabular}

\section{Details of Experimental Set-up:}

The general view of experimental set-up for three-point loading is shown in fig.2. Testing of the beam was carried out on Universal Testing Machine. Using the mechanical dial gauge with $0.01 \mathrm{~mm}$ least count the vertical deflection of the beam at centre was measured.

\section{Test Procedure:}

Load was applied in the downward direction at centre of the beam. At every load increment, deflection at centre of the beam were noted, using which load Vs deflection curves were plotted. Load increment on UTM was controlled so that the maximum load is reached in 10-15mins.

\section{Experimental methods to obtain softening portion:}

When the load was nearing the maximum, the pointer in the deflectometer on UTM showed a sudden jerk to the backward direction. But the deflection suddenly increased. From that point the load decreases gradually as deflection increases. At some point, the system becomes stable. In this way, with decreasing load, higher deflection is recorded before complete fracture of the beam. The negative inclination of the curve load Vs. deflection is called softening portion of the curve.

\section{RESULTS \& DISCUSSION}

The Load Vs Deflection curve for all 18 beams are plotted using results given below in table.

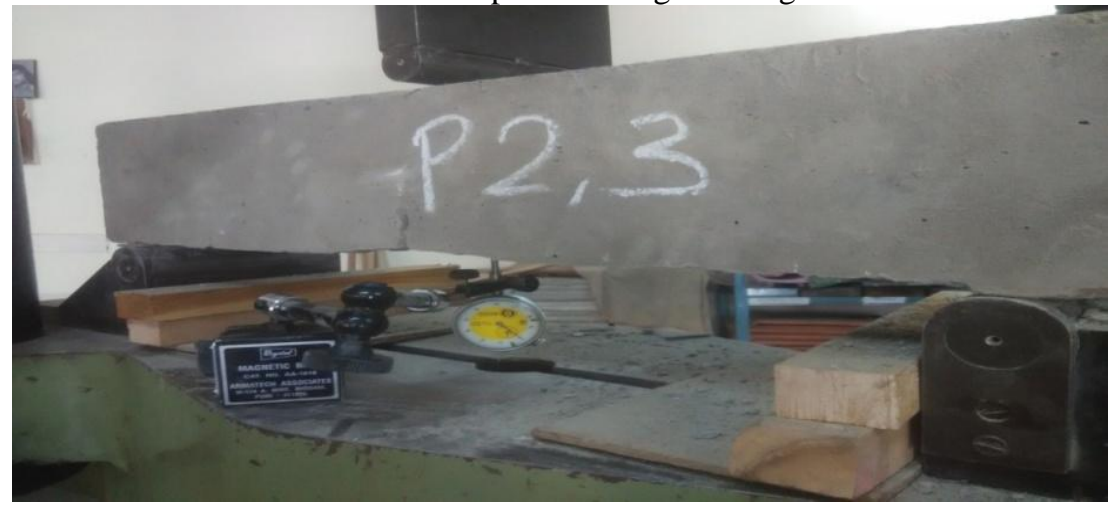

Fig. 2. Experimental set-up for three point bend test.

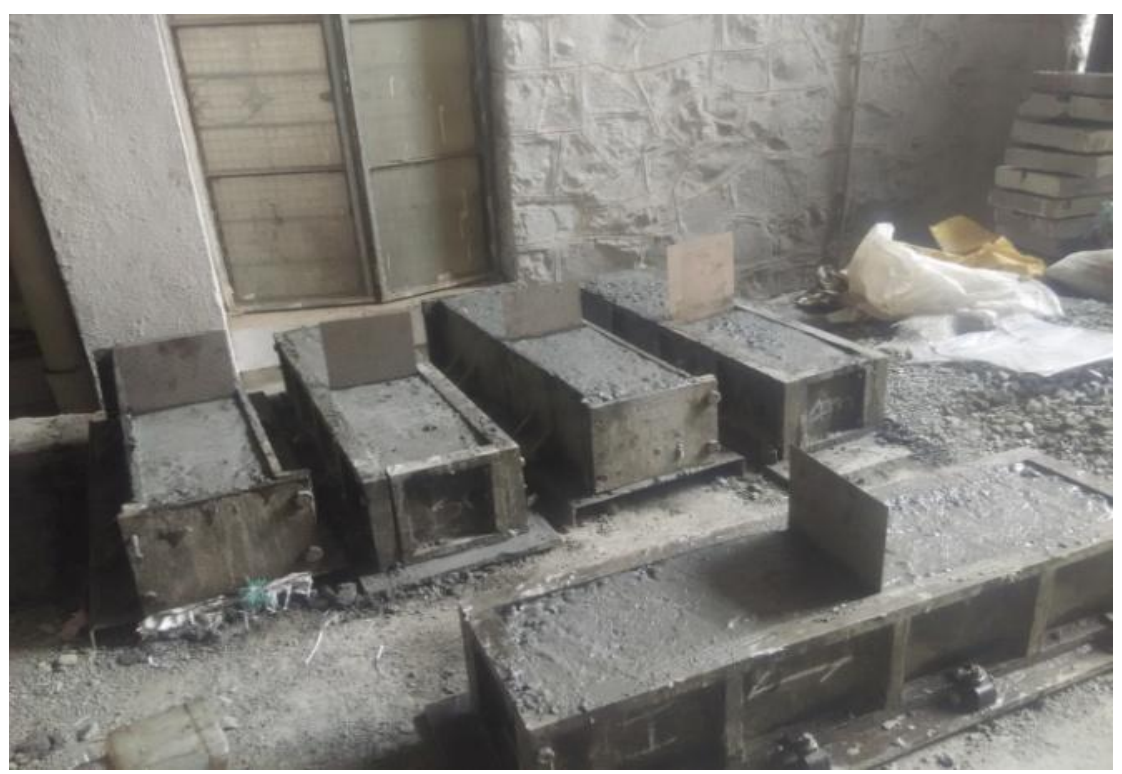

Fig. 3. Casting and development of artificial notch using ply-wood. 
Table 2. Experimental results for Beam P1

\begin{tabular}{|c|c|c|c|c|c|c|c|c|c|c|c|}
\hline \multicolumn{2}{|c|}{ BEAM P1,1 } & \multicolumn{2}{|c|}{ BEAM P1,2 } & \multicolumn{2}{|c|}{ BEAM P1,3 } & \multicolumn{2}{|c|}{ BEAM P1,4 } & \multicolumn{2}{|c|}{ BEAM P1,5 } & \multicolumn{2}{|c|}{ BEAM P1,6 } \\
\hline $\begin{array}{l}\text { LOAD } \\
(\mathrm{KN})\end{array}$ & $\begin{array}{l}\text { DISPLACE } \\
\text { MENT (mm) }\end{array}$ & $\begin{array}{l}\text { LOAD } \\
(\mathrm{KN})\end{array}$ & $\begin{array}{l}\text { DISPLACE } \\
\text { MENT }(\mathrm{mm})\end{array}$ & $\begin{array}{l}\text { LOAD } \\
(\mathrm{KN})\end{array}$ & $\begin{array}{l}\text { DISPLACE } \\
\text { MENT (mm) }\end{array}$ & $\begin{array}{l}\text { LOAD } \\
(\mathrm{KN})\end{array}$ & $\begin{array}{l}\text { DISPLACE } \\
\text { MENT }(\mathrm{mm})\end{array}$ & $\begin{array}{l}\text { LOAD } \\
(\mathrm{KN})\end{array}$ & $\begin{array}{l}\text { DISPLACE } \\
\text { MENT(mm) }\end{array}$ & $\begin{array}{l}\text { LOAD } \\
(\mathrm{KN})\end{array}$ & $\begin{array}{l}\text { DISPLACE } \\
\text { MENT (mm) }\end{array}$ \\
\hline 0 & 0 & 0 & 0 & 0 & 0 & 0 & 0 & 0 & 0 & 0 & 0 \\
\hline 0.4 & 0.02 & 0.4 & 0.01 & 0.4 & 0.01 & 0.4 & 0.02 & 0.4 & 0.03 & 0.4 & 0.01 \\
\hline 0.8 & 0.03 & 0.8 & 0.02 & 0.8 & 0.02 & 0.8 & 0.03 & 0.8 & 0.04 & 0.8 & 0.02 \\
\hline 1.2 & 0.04 & 1.2 & 0.03 & 1.2 & 0.03 & 1.2 & 0.05 & 1.2 & 0.05 & 1.2 & 0.04 \\
\hline 1.6 & 0.05 & 1.6 & 0.04 & 1.6 & 0.04 & 1.6 & 0.06 & 1.6 & 0.06 & 1.6 & 0.05 \\
\hline 2.0 & 0.06 & 2.0 & 0.05 & 2.0 & 0.05 & 2.0 & 0.07 & 2.0 & 0.07 & 2.0 & 0.07 \\
\hline 2.4 & 0.07 & 2.4 & 0.06 & 2.4 & 0.06 & 2.4 & 0.09 & 2.4 & 0.08 & 2.4 & 0.09 \\
\hline 2.8 & 0.08 & 2.8 & 0.08 & 2.8 & 0.07 & 2.8 & 0.10 & 2.8 & 0.10 & 2.8 & 0.10 \\
\hline 3.2 & 0.09 & 3.2 & 0.09 & 3.2 & 0.09 & 3.2 & 0.11 & 3.2 & 0.11 & 3.2 & 0.11 \\
\hline 4.0 & 0.12 & 4.0 & 0.12 & 4.0 & 0.12 & 4.0 & 0.12 & 4.0 & 0.12 & 4.0 & 0.12 \\
\hline 4.4 & 0.14 & 4.4 & 0.14 & 4.4 & 0.14 & 4.4 & 0.14 & 4.4 & 0.14 & 4.4 & 0.14 \\
\hline 4.8 & 0.16 & 4.8 & 0.16 & 4.8 & 0.16 & 4.8 & 0.16 & 4.8 & 0.16 & 4.8 & 0.16 \\
\hline 5.2 & 0.18 & 5.2 & 0.18 & 5.2 & 0.18 & 5.2 & 0.18 & 5.2 & 0.19 & 5.2 & 0.18 \\
\hline 5.6 & 0.20 & 5.6 & 0.20 & 5.6 & 0.21 & 5.6 & 0.20 & 5.6 & 0.20 & 5.6 & 0.20 \\
\hline 6.0 & 0.22 & 6.0 & 0.22 & 6.0 & 0.22 & 6.0 & 0.22 & 6.0 & 0.22 & 6.0 & 0.22 \\
\hline 7.0 & 0.30 & 6.8 & 0.31 & 6.6 & 0.35 & 7.2 & 0.33 & 6.5 & 0.30 & 7.3 & 0.29 \\
\hline 6.6 & 0.40 & 6.4 & 0.37 & 6.4 & 0.37 & 6.8 & 0.38 & 6.0 & 0.35 & 6.9 & 0.36 \\
\hline 6.2 & 0.45 & 6.0 & 0.41 & 6.0 & 0.41 & 6.4 & 0.42 & 5.6 & 0.41 & 6.5 & 0.45 \\
\hline 5.0 & 0.55 & 5.6 & 0.43 & 5.6 & 0.43 & 6.0 & 0.46 & 5.2 & 0.43 & 6.1 & 0.55 \\
\hline 4.6 & 0.57 & 4.2 & 0.50 & 4.2 & 0.50 & 5.0 & 0.55 & 4.2 & 0.50 & 5.0 & 0.65 \\
\hline 3.4 & 0.63 & 3.4 & 0.56 & 3.4 & 0.55 & 3.4 & 0.63 & 3.4 & 0.56 & 3.4 & 0.71 \\
\hline 3.0 & 0.65 & 3.0 & 0.59 & 3.0 & 0.59 & 3.0 & 0.69 & 3.0 & 0.59 & 3.0 & 0.79 \\
\hline 2.6 & 0.68 & 2.6 & 0.61 & 2.6 & 0.62 & 2.6 & 0.75 & 2.6 & 0.60 & 2.6 & 0.82 \\
\hline 2.2 & 0.72 & 2.2 & 0.64 & 2.2 & 0.66 & 2.2 & 0.83 & 2.2 & 0.64 & 2.2 & 0.85 \\
\hline 1.8 & 0.79 & 1.8 & 0.67 & 1.8 & 0.72 & - & - & 1.8 & 0.67 & 1.8 & 0.91 \\
\hline 1.4 & 0.91 & 1.4 & 0.75 & - & - & - & - & 1.4 & 0.75 & 1.4 & 1.2 \\
\hline 1.0 & 1.1 & 1.0 & 0.81 & - & - & - & - & 1.0 & 0.82 & - & tivate ving \\
\hline
\end{tabular}

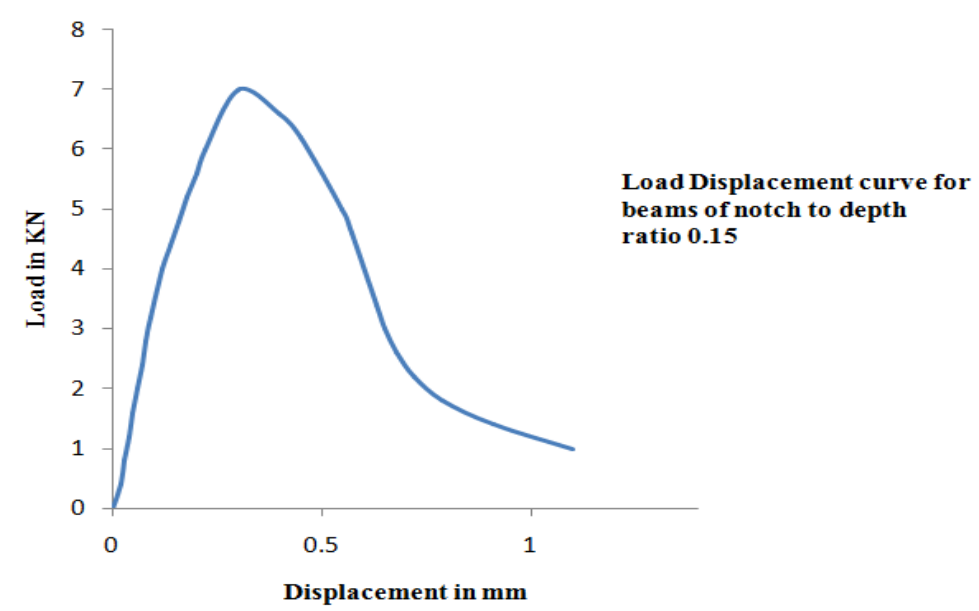

Fig 4. Load displacement curve for beam of notch to depth ratio 0.15

Table 3. Experimental results for Beam P2

\begin{tabular}{|l|l|l|l|l|l|l|l|l|l|l|l|}
\hline \multicolumn{3}{|l|}{ BEAM P2,1 } & \multicolumn{2}{l|l|}{ BEAM P2,2 } & \multicolumn{2}{l|}{ BEAM P2,3 } & \multicolumn{2}{l|}{ BEAM P2,4 } & \multicolumn{2}{l|}{ BEAM P2,5 } \\
\hline $\begin{array}{l}\text { LOAD } \\
(\mathrm{KN})\end{array}$ & $\begin{array}{l}\text { DISPLAC } \\
\text { MENT } \\
(\mathrm{mm})\end{array}$ & $\begin{array}{l}\text { LOAD } \\
(\mathrm{KN})\end{array}$ & $\begin{array}{l}\text { DISPLAC } \\
\text { MENT } \\
(\mathrm{mm})\end{array}$ & $\begin{array}{l}\text { LOAD } \\
(\mathrm{KN})\end{array}$ & $\begin{array}{l}\text { DISPLAC } \\
\text { MENT } \\
(\mathrm{mm})\end{array}$ & $\begin{array}{l}\text { LOAD } \\
(\mathrm{KN})\end{array}$ & $\begin{array}{l}\text { DISPAC } \\
\text { MENT } \\
(\mathrm{mm})\end{array}$ & $\begin{array}{l}\text { LOAD } \\
(\mathrm{KN})\end{array}$ & $\begin{array}{l}\text { DISPLAC } \\
\text { MENT } \\
(\mathrm{mm})\end{array}$ & $\begin{array}{l}\text { LOAD } \\
(\mathrm{KN})\end{array}$ & $\begin{array}{l}\text { DISPLAC } \\
\text { MENT } \\
(\mathrm{mm})\end{array}$ \\
\hline 0 & 0 & 0 & 0 & 0 & 0 & 0 & 0 & 0 & 0 & 0 \\
\hline 0.4 & 0.03 & 0.4 & 0.01 & 0.4 & 0.02 & 0.4 & 0.02 & 0.4 & 0.03 & 0.4 & 0.03 \\
\hline 0.8 & 0.07 & 0.8 & 0.03 & 0.8 & 0.04 & 0.8 & 0.06 & 0.8 & 0.06 & 0.8 & 0.05 \\
\hline 1.2 & 0.11 & 1.2 & 0.05 & 1.2 & 0.06 & 1.2 & 0.10 & 1.2 & 0.10 & 1.2 & 0.07 \\
\hline 1.6 & 0.15 & 1.6 & 0.07 & 1.6 & 0.08 & 1.6 & 0.14 & 1.6 & 0.14 & 1.6 & 0.09 \\
\hline 2.0 & 0.19 & 2.0 & 0.09 & 2.0 & 0.10 & 2.0 & 0.18 & 2.0 & 0.20 & 2.0 & 0.11 \\
\hline 2.4 & 0.24 & 2.4 & 0.11 & 2.4 & 0.12 & 2.4 & 0.22 & 2.4 & 0.24 & 2.4 & 0.13 \\
\hline 2.8 & 0.29 & 2.8 & 0.14 & 2.8 & 0.14 & 2.8 & 0.26 & 2.8 & 0.29 & 2.8 & 0.15 \\
\hline 3.2 & 0.34 & 3.2 & 0.17 & 3.2 & 0.21 & 3.2 & 0.29 & 3.2 & 0.34 & 3.2 & 0.17 \\
\hline 3.4 & 0.42 & 3.6 & 0.23 & 2.8 & 0.29 & 3.6 & 0.34 & 3.5 & 0.39 & 3.6 & 0.23 \\
\hline 3.0 & 0.50 & 3.0 & 0.31 & 2.4 & 0.35 & 3.0 & 0.39 & 3.1 & 0.43 & 3.8 & 0.28 \\
\hline 2.6 & 0.53 & 2.6 & 0.36 & 2.0 & 0.38 & 2.6 & 0.43 & 2.7 & 0.52 & 2.8 & 0.42 \\
\hline 2.2 & 0.56 & 2.2 & 0.39 & 1.8 & 0.42 & 2.2 & 0.47 & 2.2 & 0.55 & 2.4 & 0.46 \\
\hline 1.8 & 0.59 & 1.8 & 0.43 & 1.4 & 0.48 & 1.8 & 0.53 & 1.8 & 0.59 & 1.8 & 0.51 \\
\hline 1.4 & 0.63 & 1.4 & 0.49 & 1.0 & 0.56 & 1.0 & 0.69 & 1.0 & 0.63 & 1.4 & 0.56 \\
\hline
\end{tabular}




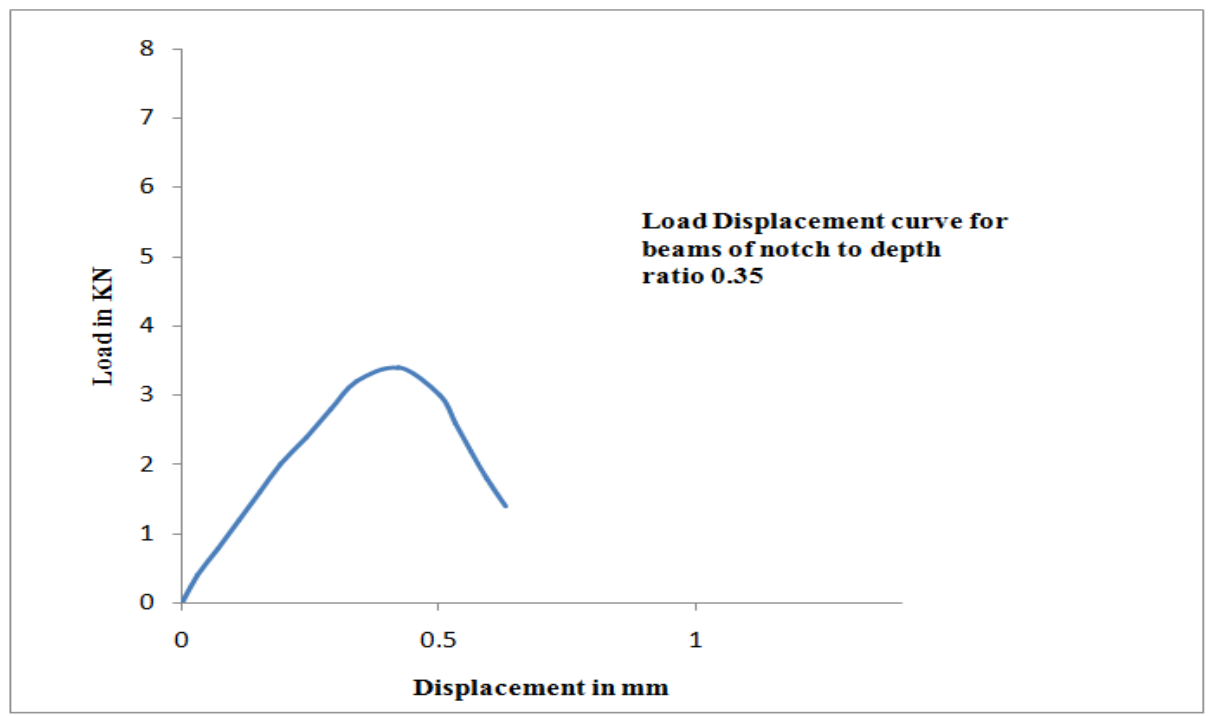

Fig 5. Load displacement curve for beam of notch to depth ratio 0.35

Table 5. Experimental results for Beam P3

\begin{tabular}{|l|l|l|l|l|l|l|l|l|l|l|l|}
\hline \multicolumn{2}{|l|}{ BEAM P3,1 } & \multicolumn{2}{l|l|l|l|}{ BEAM P3,2 } & \multicolumn{2}{l|}{ BEAM P3,3 } & \multicolumn{2}{l|}{ BEAM P3,4 } & \multicolumn{2}{l|}{ BEAM P3,6 } \\
\hline $\begin{array}{l}\text { LOAD } \\
(\mathrm{KN})\end{array}$ & $\begin{array}{l}\text { DISPLAC } \\
\text { MENT } \\
(\mathrm{mm})\end{array}$ & $\begin{array}{l}\text { LOAD } \\
(\mathrm{KN})\end{array}$ & $\begin{array}{l}\text { DISPLAC } \\
\text { MENT } \\
(\mathrm{mm})\end{array}$ & $\begin{array}{l}\text { LOAD } \\
(\mathrm{KN})\end{array}$ & $\begin{array}{l}\text { DISPLAC } \\
\text { MENT } \\
(\mathrm{mm})\end{array}$ & $\begin{array}{l}\text { LOAD } \\
(\mathrm{KN})\end{array}$ & $\begin{array}{l}\text { DISPLAC } \\
\text { MENT } \\
(\mathrm{mm})\end{array}$ & $\begin{array}{l}\text { LOAD } \\
(\mathrm{KN})\end{array}$ & $\begin{array}{l}\text { DISPLAC } \\
\text { MENT } \\
(\mathrm{mm})\end{array}$ & $\begin{array}{l}\text { LOAD } \\
(\mathrm{KN})\end{array}$ & $\begin{array}{l}\text { DISPLAC } \\
\text { MENT } \\
(\mathrm{mm})\end{array}$ \\
\hline 0 & 0 & 0 & 0 & 0 & 0 & 0 & 0 & 0 & 0 & 0 \\
\hline 0.4 & 0.04 & 0.4 & 0.02 & 0.4 & 0.03 & 0.4 & 0.03 & 0.4 & 0.02 & 0.4 & 0.02 \\
\hline 0.8 & 0.1 & 0.8 & 0.04 & 0.8 & 0.08 & 0.8 & 0.06 & 0.8 & 0.05 & 0.8 & 0.06 \\
\hline 1.2 & 0.14 & 1.2 & 0.06 & 1.2 & 0.12 & 1.2 & 0.09 & 1.2 & 0.08 & 1.2 & 0.10 \\
\hline 1.6 & 0.19 & 1.6 & 0.08 & 1.6 & 0.16 & 1.6 & 0.12 & 1.6 & 0.11 & 1.6 & 0.14 \\
\hline 2.0 & 0.25 & 2.0 & 0.10 & 2.0 & 0.21 & 2.0 & 0.22 & 2.0 & 0.16 & 2.0 & 0.23 \\
\hline 2.2 & 0.33 & 2.6 & 0.15 & 2.5 & 0.26 & 2.4 & 0.28 & 2.3 & 0.21 & 1.6 & 0.31 \\
\hline 1.8 & 0.47 & 1.8 & 0.29 & 1.8 & 0.38 & 1.8 & 0.41 & 1.4 & 0.37 & 1.4 & 0.36 \\
\hline 1.4 & 0.55 & 1.0 & 0.41 & 1.0 & 0.47 & 1.4 & 0.47 & 1.0 & 0.45 & 1.2 & 0.41 \\
\hline
\end{tabular}

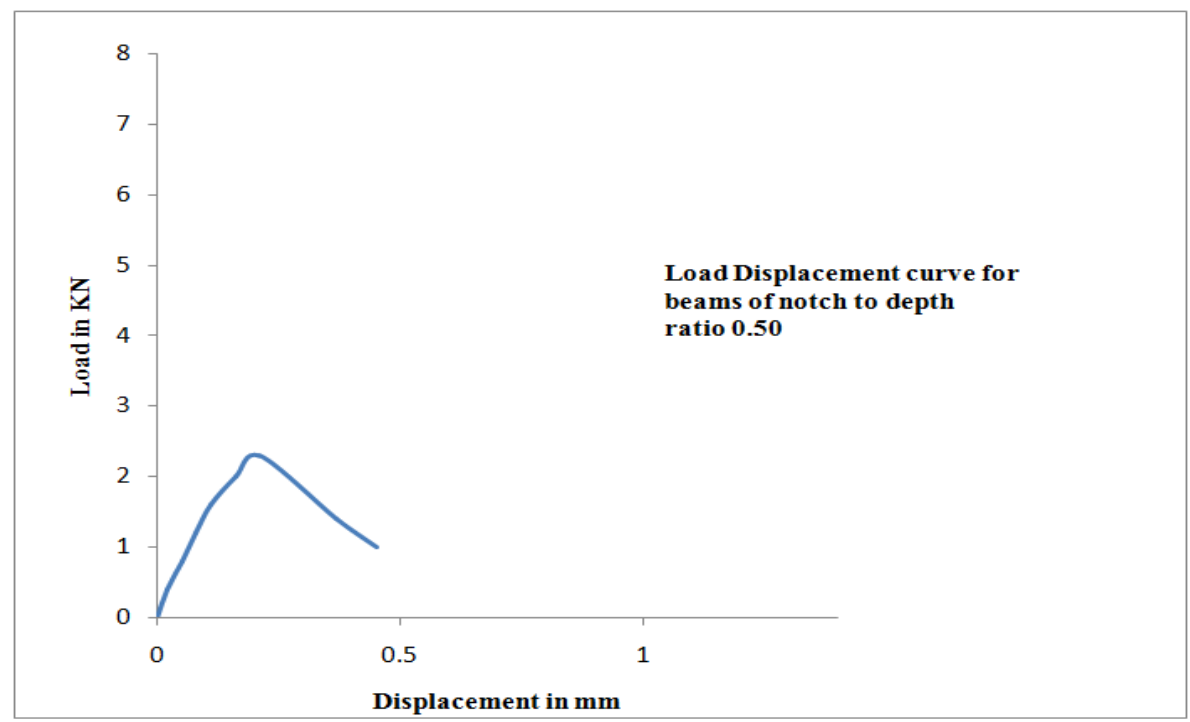

Fig 6. Load displacement curve for beam of notch to depth ratio 0.50

We can observe from all Load Vs Displacement curve for each beam that the curve is a straight line before it reaches to max. displacement. When its nearing to max. displacement there is a non-linearity in the curve and a sudden increase in displacement when we reach to max load. Beyond that, the load gradually decreases but displacement keeps on increasing till it reaches to failure. A portion after max load attained is a softening portion of a curve. Such strain hardening and strain softening shows concrete is a Quasi-brittle material. Some of the equations used: 
1) Brown and Swarley's equation for (S / D ) $=4$ for Geometry Function ' $Y$ ', $\mathrm{Y}(\mathrm{a} / \mathrm{W})=1.93-[3.07 *(\mathrm{a} / \mathrm{W})]+\left[14.53 *(\mathrm{a} / \mathrm{W})^{2}\right]-\left[23.98 *(\mathrm{a} / \mathrm{W})^{3}\right]+$ $\left[25.22 *(\mathrm{a} / \mathrm{W})^{4}\right]$

2) Fracture Energy, $G_{f}=A /[(W-a) * B]$

3) Bending Moment, B.M $=(\mathrm{P} * \mathrm{~S}) / 4+\mathrm{BM}$ due to self wt. of beam

4) Stress Intensity Factor (Fracture Toughness), $\mathrm{K}_{\mathrm{IC}}=(6 * \mathrm{Y} * \mathrm{BM} * \sqrt{\mathrm{a}}) /\left(\mathrm{B}^{2} * \mathrm{~W}\right)$

Table 6. Values of Fracture Energy and Stress Intensity Factor

\begin{tabular}{|l|l|l|l|l|l|l|l|l|l|}
\hline Beam & $\begin{array}{l}\text { Notch to } \\
\text { depth ratio } \\
(\mathrm{a} / \mathrm{W})\end{array}$ & $\begin{array}{l}\text { Notch } \\
\text { depth 'a' } \\
(\mathrm{m})\end{array}$ & $\begin{array}{l}\text { Max. } \\
\text { load 'P' } \\
(\mathrm{KN})\end{array}$ & $\begin{array}{l}\text { Area } \\
\text { under } \\
\text { Curve 'A' }\end{array}$ & $\begin{array}{l}\text { Bending } \\
\text { Moment } \\
\text { 'BM' }\end{array}$ & $\begin{array}{l}\mathrm{G}_{\mathrm{f}} \\
(\mathrm{N} / \mathrm{m})\end{array}$ & $\mathrm{Y}$ & $\begin{array}{l}\mathrm{K}_{\mathrm{IC}} \\
\left(\mathrm{MPa} \mathrm{m}^{1 / 2}\right)\end{array}$ & $\begin{array}{l}\mathrm{G}_{\mathrm{c}} \\
\left(\mathrm{N} / \mathrm{m}^{\prime}\right)\end{array}$ \\
\hline & & & & & & & & \\
\hline P1,1 & 0.15 & 0.0225 & 7.0 & 4.01 & 1.067 & 209.67 & 1.728 & 491.7 & 9.673 \\
\hline P1,2 & 0.15 & 0.0225 & 6.8 & 3.443 & 1.037 & 180.03 & 1.728 & 477.9 & 9.136 \\
\hline P1,3 & 0.15 & 0.0225 & 6.6 & 3.678 & 1.01 & 192.31 & 1.728 & 465.5 & 8.667 \\
\hline P1,4 & 0.15 & 0.0225 & 7.2 & 3.854 & 1.097 & 201.52 & 1.728 & 505.6 & 10.22 \\
\hline P1,5 & 0.15 & 0.0225 & 6.5 & 3.568 & 0.992 & 186.56 & 1.728 & 457.2 & 8.361 \\
\hline P1,6 & 0.15 & 0.0225 & 7.3 & 4.11 & 1.11 & 214.91 & 1.728 & 511.6 & 10.47 \\
\hline & & & & & & & & & \\
\hline P2,1 & 0.35 & 0.0525 & 3.4 & 1.388 & 0.527 & 94.91 & 1.986 & 426.2 & 7.964 \\
\hline P2,2 & 0.35 & 0.0525 & 3.6 & 1.349 & 0.557 & 92.24 & 1.986 & 450.5 & 9.624 \\
\hline P2,3 & 0.35 & 0.0525 & 3.2 & 1.324 & 0.497 & 90.53 & 1.986 & 401.9 & 7.461 \\
\hline P2,4 & 0.35 & 0.0525 & 3.6 & 1.365 & 0.557 & 93.33 & 1.986 & 450.5 & 9.235 \\
\hline P2,5 & 0.35 & 0.0525 & 3.5 & 1.366 & 0.527 & 93.40 & 1.986 & 426.2 & 8.694 \\
\hline P2,6 & 0.35 & 0.0525 & 3.6 & 1.398 & 0.557 & 95.59 & 1.986 & 450.5 & 8.118 \\
\hline & & & & & & & & & \\
\hline P3,1 & 0.50 & 0.0750 & 2.2 & 0.838 & 0.347 & 74.49 & 2.606 & 440.4 & 7.757 \\
\hline P3,2 & 0.50 & 0.0750 & 2.6 & 0.834 & 0.407 & 74.13 & 2.606 & 516.5 & 9.389 \\
\hline P3,3 & 0.50 & 0.0750 & 2.5 & 0.816 & 0.392 & 72.53 & 2.606 & 497.5 & 8.892 \\
\hline P3,4 & 0.50 & 0.0750 & 2.4 & 0.825 & 0.377 & 73.33 & 2.606 & 478.4 & 8.776 \\
\hline P3,5 & 0.50 & 0.0750 & 2.3 & 0.812 & 0.362 & 72.18 & 2.606 & 459.4 & 8.442 \\
\hline P3,6 & 0.50 & 0.0750 & 2.0 & 0.791 & 0.317 & 70.31 & 2.606 & 402.3 & 6.474 \\
\hline
\end{tabular}

From above obtained results we can take average and summarize as follows:

Table 7. Summary

\begin{tabular}{|l|l|l|l|l|l|l|l|}
\hline $\begin{array}{l}\text { Beam } \\
\text { Type }\end{array}$ & $\begin{array}{l}\text { Max. Load } \\
(\mathrm{KN})\end{array}$ & $\begin{array}{l}\text { Displacement at } \\
\text { max. load }(\mathrm{mm})\end{array}$ & $\begin{array}{l}\text { Failure Load } \\
(\mathrm{KN})\end{array}$ & $\begin{array}{l}\text { Max. Displacement } \\
(\mathrm{mm})\end{array}$ & $\begin{array}{l}\mathrm{G}_{\mathrm{f}} \\
(\mathrm{N} / \mathrm{m})\end{array}$ & $\begin{array}{l}\mathrm{K}_{\mathrm{IC}} \\
\left(\mathrm{MPa} \mathrm{m}^{1 / 2}\right)\end{array}$ & $\begin{array}{l}\mathrm{G}_{\mathrm{c}} \\
(\mathrm{N} / \mathrm{m})\end{array}$ \\
\hline P1 & 6.90 & 0.31 & 1.40 & 0.91 & 197.5 & 484.92 & 9.42 \\
\hline P2 & 3.52 & 0.31 & 1.20 & 0.59 & 93.33 & 460.97 & 8.52 \\
\hline P3 & 2.33 & 0.40 & 0.46 & 72.83 & 454.42 & 8.29 \\
\hline
\end{tabular}

From table 7, we can see that max. load for all type of beams differ from each other. As notch to depth ratio increases max load carrying capacity decreases. Thus, type P1 beams takes more load than other two type. But failure load of all three types of beams almost remains same. Displacement observed at max load also does not have much of difference. Max displacement of all three types of beams vary. From load Vs displacement curve, type P1 is more ductile than other two types. Ductility decreases as notch to depth ratio increases.

Fracture Energy or Fracture Toughness " $\mathrm{G}_{\mathrm{f}}$ " calculated for type P2 \& type P3 do not have much difference but type P1 has some abrupt value. The reason is due to boundary effect. As notch created in type P1 was very close to boundary of beam the width of Fracture Process Zone (FPZ) is enormous and thus the fracture energy obtained is abrupt and thus boundary effect was observed in type P1 beam. Due to boundary effect we will neglect $G_{f}$ values of type $P 1$ and therefore the range of fracture energy is $72-93 \mathrm{~N} / \mathrm{m}$.

Stress intensity factor " $\mathrm{K}_{\mathrm{IC}}$ " is calculated using Brown and swarley's equation. " $\mathrm{K}_{\mathrm{IC}}$ " is also called as Toughness. Both fracture toughness " $\mathrm{G}_{\mathrm{f}}$ " and toughness " $\mathrm{K}_{\mathrm{IC}}$ " are one and the same. They define the propagation of cracks one in energy and other in stress respectively. The range of " $\mathrm{K}_{\mathrm{IC}}$ " is $454-484 \mathrm{MPa} \mathrm{m}^{1 / 2}$.

Energy release rate $G_{c}$ defined by Griffiths considering concrete as a brittle material is also calculated here. Values determined experimentally for $\mathrm{G}_{\mathrm{c}} \& \mathrm{G}_{\mathrm{f}}$ should be equal but it is found they are not. Thus, we can confirm concrete is not a brittle material. Also, $G_{c}$ determines only the energy dissipated in front of notch to propagate till failure whereas $\mathrm{G}_{\mathrm{f}}$ gives the total energy dissipated in the beam i.e. to propagate notch, to create FPZ in front of notch and micro cracks in beams therefore the difference in value. The range of $G_{c}$ is found out to be 8 to 10 $\mathrm{N} / \mathrm{m}$. 

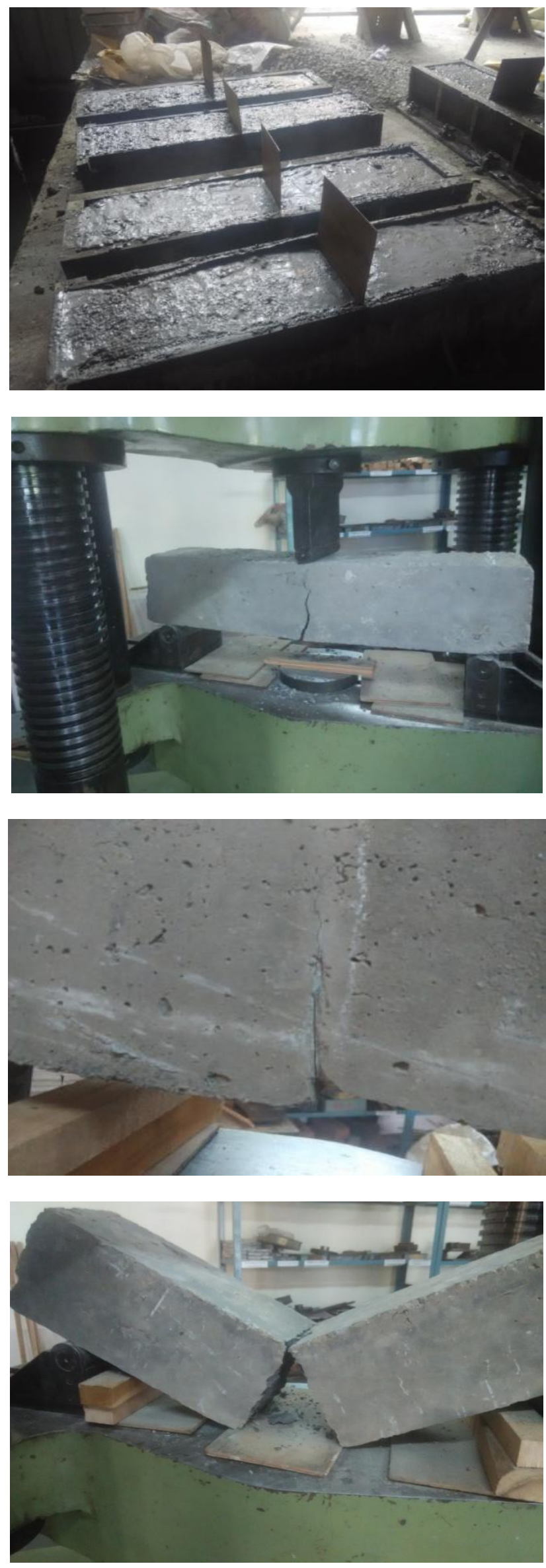


\section{CONCLUSION}

Based on testing of 18 beams and evaluating the values of Fracture Energy, following conclusion can be drawn:

1) The study invokes a primary approach based on concrete fracture mechanics that describes the nonlinear aspects of concrete behaviour through load-load line responses for a range of a/W ratios and help to understand the failure mechanisms and load bearing capacity of concrete structures.

2) Strain hardening and strain softening was studied through load vs displacement curve.

3) Failure of all beams was through pre-notch which was expected.

4) Deflection of beams is linear in pre-peak curve and increases abruptly when reaches peak load.

5) Fracture Energy decreases as notch to depth ratio increases.

6) The range of Fracture Energy is from $72 \mathrm{~N} / \mathrm{m}$ to $93 \mathrm{~N} / \mathrm{m}$.

7) Boundary effect was observed in type P1 beams i.e. beams with notch to depth ratio of 0.15 .

\section{FUTURE SCOPE}

The concept of Fracture mechanics is still in developing stages and so much to find before we apply in practical world. Following are some future study which can be done to the present work:

1) Developing a FEM model for the present work and compare the experimental and numerical work.

2) Testing of various geometrically similar beams with different sizes having constant span to depth ratio and varying notch to depth ratio.

3) Experimental work (2) can be extended by varying span to depth ratio.

\section{REFERENCES}

[1]. ACI Committee 446.1R (chaired by ZDENEK P. BAZANT), "Fracture Mechanics of Concrete: Concepts, Models' and Determination of Material Properties", Fracture Mechanics.

[2]. ACI Committee446 (chaired by Vellore Gopalaratnam), "Finite Element Analysis of Fracture in Concrete Structures: State of The Art", 446.3R-97.

[3]. BARENBLATT G. I. 1959," The formation of equilibrium cracks during brittle fracture. General ideas and hypothesis. Axiallysymmetric cracks", Prikladnaya Matematikai Mekhanika, Vol. 23, No.3, pp. 434-444.

[4]. Bazant, Z. P., 1985, "Fracture Mechanics and Strain-Softening in Concrete," Preprints,US.-Japan Seminar on Finite Element Analysis of Reinforced Concrete Stuctures, Tokyo, V. 1, pp. 47-69.

[5]. Hillerborg, A.; Modeer, M.; and Petersson, P. E., 1976, "Analysis of Crack Formation and Crack Growth in Concrete by Means of Fracture Mechanics and Finite Elements," Cem. and Conc. Res., V. 6, 773-782.

[6]. Griffith, A. A., 1920, "The Phenomenon of Rupture and Flow in Solids," Philosophical Transactions, Royal Society of London, Series A, V. 221, pp.163-198.

[7]. David Roylance, June 14, 2001, "Introduction to Fracture Mechanics", Department of Materials Science and Engineering, Massachusetts Institute of Technology,Cambridge, MA 02139.

[8]. Wittmann, F. H., (ed.): 1983, "Fracture Mechanics of Concrete", Elsevier Science Publishers Company Inc. Proceedings of a Conference in Lausanne.

[9]. Materials and Structures/Materials et Constructions, Vol. 33, January-February 2000, pp 3-5 "RILEM TC 162-TDF : Test and design methods for steel fibre reinforced concrete".

[10]. N. Trivedi, R.K. Singh, J. Chattopadhyay, March 2015," A comparative study on three approaches to investigate the size independent fracture energy of concrete", Elsevier, Engineering Fracture Mechanics 138 (2015) 49-62.

[11]. Xiufang Zhang, ShilangXu, March 2011, "A comparative study on five approaches to evaluate double-K fracture toughness parameters of concrete and size effect analysis", Elsevier, Engineering Fracture Mechanics 78 (2011) 2115-2138.

[12]. S.Y. Alam, A. Loukili, F. Grondin, E. Rozière, June 2015, "Use of the digital image correlation and acoustic emissiontechnique to study the effect of structural size on cracking of reinforced concrete", Elsevier, Engineering Fracture Mechanics 143 (2015) 17-31.

[13]. A. Nazari, J.G. Sanjayan, June 2015, "Stress intensity factor against fracture toughness in functionally graded geo-polymers", Elsevier, Archives of Civil and Mechanical Engineering, ACME-321.

[14]. B.L. Karihaloo, H.M. Abdalla and T.Imjai, 2003, "A Simple method of determining the true specific fracture energy of concrete", Magazine of Concrete Research, 55, No.5, October 471-481.

[15]. Bhushan L. Karihaloo, 1995, "Fracture Mechanics \& Structural concrete", Longman Scientific \& Technical. 